\title{
O REGISTRO CIVIL DA CRIANÇA INTERSEX COMO GARANTIA DO DIREITO À IDENTIDADE
}

\author{
Caroline Lovison Dori* \\ Bruno Bortolucci Baghim**
}

Resumo: A obrigatoriedade de informar o sexo do neonato para fins de assentamento no Registro Civil prejudica o registro do nascido intersex, considerando a dificuldade na identificação do seu sexo biológico. A omissão na Lei 6.015/1973 desrespeita o direito à identidade do indivíduo intersex e gera um impasse aos pais no que tange ao procedimento de registro. De outro modo, a busca precoce pela adequação do corpo dentro do binarismo homemmulher por meio de procedimentos cirúrgicos e outros tratamentos definitivos retira a autonomia da criança intersex. Com o uso do método dedutivo e mediante análise bibliográfica, o presente trabalho busca contextualizar o tratamento conferido ao registro civil dos intersexuais com vistas a fomentar a discussão sobre a garantia do seu direito à identidade.

Palavras-chave: intersex; registro civil; identidade; direito da personalidade; direito da criança.

\section{THE CIVIL REGISTRY OF THE INTERSEX CHILD AS GUARANTEE OF THE RIGHT TO IDENTITY}

\begin{abstract}
The obligation to inform the sex of the newborn for settlement in the Civil Registry prejudices the registration of the intersex born, considering the difficulty in the identification of their biological sex. The omission in Law 6.015/1973 disrespects the right to identity of the intersex individual and creates an impasse to parents with regard to registration procedure. Otherwise, an early search for the adequacy of the body within the binarism man-woman through surgical procedures and other definitive treatments removes the autonomy of the intersex child. With the use of deductive method and through bibliographical analysis, the present work seeks to contextualize the treatment given to the civil registry of intersexuals in order to foment the discussion about the guarantee of their right to identity.
\end{abstract}

Key words: intersex; civil registry; identity; right of personality; right of the child.

\footnotetext{
* Mestranda do Programa de Pós-Graduação em Ciência Jurídica da Universidade Estadual do Norte do Paraná (UENP). Pós-graduada em Direito Processual Civil pela Instituição Damásio Educacional e pelo Centro Universitário Internacional (UNINTER). Bacharela em Direito pela Universidade Estadual do Norte do Paraná (UENP). Bolsista da Coordenação de Aperfeiçoamento de Pessoal de Nível Superior (CAPES). Piraju, São Paulo, Brasil. E-mail: caroline_cld@hotmail.com

${ }^{* *}$ Defensor Público do Estado de São Paulo desde 2009, com atuação na área criminal. Coordenador Regional da Defensoria Pública em Marília. Coordenador Regional da Escola da Defensoria Pública do Estado (EDEPE). Exmembro do Núcleo de Defesa da Diversidade e da Igualdade Racial da Defensoria Pública do Estado. Professor da Escola da Magistratura do Paraná, do Curso Ênfase, e da Pós-Graduação em Direito Penal e Processo Penal da Faculdade de Direito da Alta Paulista (FADAP), em Tupã-SP. Graduado em Direito pela Universidade Estadual Paulista "Júlio de Mesquita Filho" (UNESP-Campus Franca). Especialista em Ciências Penais e Direito Constitucional. Associado ao Instituto Brasileiro de Ciências Criminais (IBCCRIM). Mestrando do Programa de Pós-Graduação em Ciência Jurídica da Universidade Estadual do Norte do Paraná (UENP). Marília, São Paulo, Brasil. E-mail: bbaghim@ hotmail.com
} 


\section{INTRODUÇÃO}

Os direitos da personalidade se apresentam como viés constitucional do direito civil, superando a proposição e a dicotomia entre direito público e privado, ressignificando o direito privado tradicionalmente caracterizado pela proteção ao patrimônio.

Dentre os direitos da personalidade, o direito à identidade se caracteriza por permitir a individualização da pessoa e evitar confusão com outra. Constitui-se de elementos que tornam possível identificar o indivíduo na sociedade, podendo ser associado ao nome (visão mais tradicional) e a outros caracteres, como a voz, a imagem, e à identidade sexual.

A princípio, a identidade sexual é estabelecida no momento do nascimento, com a análise da genitália externa e indicação do indivíduo como pertencente ao sexo feminino ou masculino. Tal identificação é utilizada para fins de assentamento no registro civil, sendo obrigatória a identificação do sexo no momento da lavratura da certidão de nascimento, conforme estabelecido na Lei 6.015/1973, Lei de Registros Públicos.

Contudo, mencionada lei se omite quanto aos indivíduos intersex, nascidos com ambiguidade genital ou anomalia que dificulta a identificação do sexo biológico apenas pela análise do órgão genital externo. O silêncio legal inviabiliza o registro civil sem a definição de sexo do indivíduo.

Diante da necessidade jurídica em identificar sexualmente o indivíduo dentro da binariedade homem/mulher, pais e médicos se veem em uma situação complexa, eventualmente optando pela cirurgia de adequação sexual ou outros tratamentos definitivos. Nesse ínterim, a autonomia do nascido intersex é desrespeitada, ante à sua condição de vulnerabilidade.

A inviabilidade do registro civil sem a identificação do sexo acarreta danos que ultrapassam a identificação sexual, dando invisibilidade ao sujeito no plano jurídico e desrespeitando a garantia de outros direitos que dependente do registro.

Considerando o problema proposto, e com a utilização do método de pesquisa dedutivo, o presente trabalho busca explorar possibilidades ao registro do nascido intersex, viabilizando a autonomia do indivíduo na realização de sua escolha. Por meio da análise do direito à identidade no âmbito dos direitos da personalidade, bem como da Lei de Registros Públicos e de projetos de lei que disponham sobre o tema, a pesquisa se desenvolve com o fito de se garantir o registro civil ao nascido intersex de maneira simples e facilitada, independente da necessidade de se indicar o sexo no registro de nascimento ou de se proceder a tratamentos médicos invasivos e irreversíveis.

Rev. de Gênero, Sexualidade e Direito | e-ISSN: 2525-9849 | Porto Alegre | v. 4 | n. 2 | p. 137 - 154 | Jul/Dez. 2018 


\section{INTERSEXUALIDADE}

O debate sobre a intersexualidade vem ganhando espaço nas últimas décadas, ultrapassando os estudos médicos e se destacando também no âmbito das ciências humanas, diante das discussões sobre sexualidade e gênero. No Brasil, a temática tem se destacado recentemente, trazendo visibilidade ao intersex e à proteção de sua identidade pessoal.

O termo intersex tem origem médica, "mas foi assumido pelos ativistas para nomear as pessoas que nascem com corpos que não se encaixam no que é estabelecido socialmente como corpos masculinos ou femininos" (BENTO, 2011, p. 132).

A partir da década de 1990 passou a ser usado fora do âmbito médico, e atualmente é chamado de Distúrbio de Diferenciação Sexual, e considerado uma atipia genital, porém ainda existem poucos estudos sobre a intersexualidade (DIAS, 2017). Assim, "a partir da década de 90 o termo 'intersex' deixa de ser exclusivo ao campo biológico e médico, sendo apropriado pelos cientistas sociais e ativistas que constroem novos significados sobre este conceito" (CANGUÇÚ-CAMPINHO, 2012, p. 20).

Dessa forma, dá-se preferência aos termos intersexo ou intersexualidade nas Ciências Sociais, enquanto nas áreas Biomédicas utiliza-se as nomenclaturas ADS (Anomalia do Desenvolvimento Sexual) ou DDS (Distúrbio de Diferenciação Sexual), conforme Fraser e Lima (2012, p. 04).

A indeterminação do sexo do indivíduo é causada por alguma síndrome, produzindo ou não ambiguidade na genitália e dificultando uma definição sexual precisa (BARROS, 1990, p. 13).

A definição do sexo do indivíduo, de acordo com Barros (1990, p. 13-14), obedece a determinados critérios, consistindo em: sexo genético, o qual indica a constituição cromossômica (XX feminino e XY masculino); sexo gonadal, relativo à formação da estrutura morfológica das gônadas (com o cromossomo Y a gônada se desenvolve em direção ao masculino, de maneira que o tecido se volta à forma testicular); sexo fenotípico, respeitando às condições hormonais, sendo "responsável pela estrutura morfológica dos condutos genitais e dos genitais externos" (o sexo fenotípico depende "da normalidade endócrina e da produção regular das enzimas"). Desse modo, o sexo biológico é constituído de inúmeros fatores, dentro dos quais podem ocorrer falhas na determinação e diferenciação entre os sexos feminino ou masculino.

Rev. de Gênero, Sexualidade e Direito | e-ISSN: 2525-9849 | Porto Alegre | v. 4 | n. 2 | p. 137 - 154 | Jul/Dez. 2018 
A definição do sexo do indivíduo se dá, em regra, com base na identificação do sexo fenotípico, de maneira que o bebê é registrado como pertencente ao sexo masculino quando exibe ou há a predominância dos genitais externos masculinos; sem maiores indagações quanto ao sexo genético ou gonadal (BARROS, 1990, p. 16).

O sexo biológico é definido entre homem ou mulher de acordo com as características dos genitais apresentados pelo indivíduo tão logo nasce. Tal constatação pode gerar complexidade quando houver ambiguidade genital ou divergência entre os genitais e o sexo genético, por exemplo, casos estes em que a intersexualidade é manifestada.

\begin{abstract}
O recém-nascido $(\mathrm{RN})$ tem o sexo definido pelo aspecto dos órgãos genitais externos e quando não se consegue fazer essa definição estamos diante de uma ambiguidade genital. Fala-se em estado intersexual quando, pelos parâmetros anatômicos convencionais, não se define o sexo biológico da pessoa. Esses estados podem coexistir com ou sem ambiguidade dos órgãos genitais internos. Assim, a ambiguidade genital é um sinal de alerta para uma alteração orgânica subjacente e nos remete à já citada urgência da definição sexual. A ausência de apresentação ambígua dos genitais externos retarda a apresentação do problema, que irá eclodir na adolescência, por falta de desenvolvimento puberal ou por seu desenvolvimento inadequado. (CERQUEIRA, 2011, p. 51).
\end{abstract}

Os problemas de ambiguidade sexual se mostram apenas depois do nascimento e, em diversas vezes, são notados somente na puberdade ou no início da vida sexual adulta (CERQUEIRA, 2011, p. 52).

Ainda que o sexo seja facilmente identificado pela observação dos genitais externos e considerado aparentemente normal sob o ponto de vista médico, na puberdade ou já na fase adulta, a pessoa intersex pode apresentar alterações físicas diversas das biologicamente esperadas (considerando o sexo fenotípico evidenciado quando do seu nascimento). Dessa forma, pode surgir, apenas nesse momento, a necessidade de se realizarem exames clínicos que constatem o sexo genético, e então atestem a condição de intersexualidade.

Nesses casos é indicado o acompanhamento de ginecologistas ou urologistas, além de psiquiatras e psicólogos preparados para auxiliar a pessoa na sua tomada de decisão de permanência ou troca de sexo (CERQUEIRA, 2011, p. 52). A possibilidade de permanência ou de troca de sexo ocorre uma vez que houve anterior determinação da identidade sexual pelos pais ou médicos, quando do nascimento, e baseada nos genitais externos que se mostravam dentro da binariedade homem/mulher.

De modo diverso, a intersexualidade pode ser manifestada logo quando do nascimento, constatando-se pela ambiguidade da genitália externa. Nesses casos, surge a discussão sobre a 
realização de cirurgia ou tratamentos hormonais para encaixar o intersex dentro dos padrões do que é considerado uma genitália masculina ou feminina.

Para a medicina, o indivíduo intersex não apresenta sexo cromossômico, genitália externa ou sistema reprodutivo interno dentro do padrão de normalidade, havendo, portanto, urgência na reparação. Contudo, "as repercussões individuais, sociais, legais, afetivas e até mesmo sexuais de quem não tem o sexo definido, não pode alijá-lo do processo de escolha”, inclusive pelo fato de que a opção corresponde à identidade de gênero pode se revelar depois de determinada idade (DIAS, 2017).

É importante pontuar que a identidade sexual aqui exposta confunde-se com a identidade de gênero, considerando que os registros civis brasileiros não fazem diferenciação de uma ou outra identificação pessoal ${ }^{1}$.

De todo modo, quando a condição de intersexualidade é observada logo no nascimento, as complexidades inerentes ao caso geram dúvidas sobre como proceder com relação ao aspecto físico, social, psicológico e jurídico do indivíduo.

Para Barros (1990, p. 16), compete ao médico (de preferência um geneticista), fazer a correta indicação na escolha do sexo a ser definido, considerando, além das características físicas do indivíduo, o sexo de criação e o comportamento e a identificação sexual (sexo psicossocial).

Tão logo constatado o diagnóstico da intersexualidade, deve o indivíduo ser encaminhado ao tratamento adequado, de maneira que a demora pode gerar graves consequências psicológicas (CUNHA, 2014, p. 131). Destaca-se que consideramos importante a urgência no tratamento psicológico do indivíduo assim que se constate a sua condição de

\footnotetext{
${ }^{1}$ Nesse sentido, transexuais e travestis que se identificam com o gênero feminino, por exemplo, poderão alterar sua documentação para fazer constar sexo feminino, tal como decidido nos tribunais pátrios e, especialmente, pelo Supremo Tribunal Federal em março do corrente ano. Com efeito, a Ação Direta de Inconstitucionalidade $\mathrm{n}^{\circ} 4275$, apresentada pelo Procuradoria Geral da República em 2009, requeria o reconhecimento do direito de transexuais em realizar a substituição do prenome e do sexo no registro civil, independentemente da cirurgia de transgenitalização. A ação tinha como fundamento a interpretação conforme a Constituição do artigo 58 da Lei 6.015/73, considerando o nome social como um apelido público notório, com o qual os transexuais são identificados pela família e amigos. O Tribunal decidiu, em março de 2018 , pela procedência da ação, por maioria dos votos, dando interpretação conforme a Constituição e o Pacto de São José da Costa Rica ao art. 58 da referida lei, viabilizando que transgêneros tenham o direito à substituição de prenome e sexo diretamente no registro civil, independentemente da cirurgia de transgenitalização, ou da realização de tratamentos hormonais ou patologizantes. Na referida decisão, o STF julgou procedente a possibilidade de alterar o prenome e o sexo no registro civil, diante da identidade de gênero na qual a pessoa transgênero expressamente se manifesta e se sente pertencente. Eventuais tratamentos hormonais ou cirurgias serão realizados após a sua manifestação de vontade, garantindo a sua autonomia. (BRASIL. Supremo Tribunal Federal. Ação Direta de Inconstitucionalidade no 4.275/DF. Relator Ministro Marco Aurélio. Julgado em 01 mar. 2018. Disponível em: $<$ http://portal.stf.jus.br/processos/detalhe.asp?incidente=2691371>. Acesso em: 20 jun. 2018).
} 
intersexualidade; contudo, a urgência na realização de intervenção cirúrgica, tratamento hormonal ou qualquer método invasivo pode gerar maiores transtornos, especialmente se o indivíduo for uma criança. Sendo assim, deve-se considerar a autoidentificação sexual e de gênero da pessoa intersex, com vistas a garantir o melhor tratamento ou, eventualmente, a sua não realização, caso assim opte o indivíduo, considerando sempre a necessidade de se proceder ao tratamento psicológico para o intersex e sua família.

Ainda que exista a possibilidade de alterar cirurgicamente as ambiguidades genitais, deve-se considerar que a identidade sexual depende de fatores biológicos, sociais e psicológicos, que ultrapassam o simples aspecto físico exterior do indivíduo.

Portanto, o acompanhamento psicológico se faz fundamental para que seja tomada a melhor decisão, seja na realização ou não de cirurgia de adequação sexual, considerando que eventual cirurgia precoce pode dificultar ou inviabilizar alteração posterior.

Ademais, a preocupação estética evidenciada com a cirurgia de "correção" da genitália da criança mostra-se contrária ao posicionamento adotado pela IntersexSociety of North America (ISNA). Para referida instituição, a cirurgia constitui uma atitude precoce, cuja defesa em prol do conforto dos pais se apresenta como um argumento muito frágil (SOUZA; SILVA, 2018, p. 140-141).

Para Dias (2017), deve ser assegurada a possibilidade de escolha autônoma à pessoa intersex. Com exceção dos casos em que existe risco à vida, a intervenção cirúrgica se mostra desnecessária, e afeta a livre escolha da criança, que se encontra em situação vulnerável em relação aos pais e aos médicos.

Em âmbito médico, a Resolução 1.664/2003, do Conselho Federal de Medicina, dispõe sobre o tratamento de portadores de anomalias de diferenciação sexual, ressaltando a urgência na sua realização, com a garantia de investigação precoce para uma definição adequada do gênero, conforme artigo $2^{\circ}$. Em seu artigo $4^{\circ}$ estabelece a necessidade de acompanhamento com equipe multidisciplinar para definição final e adoção do sexo, de maneira que o paciente "que apresenta condições" deve participar ativamente da decisão. A Resolução também aponta, anexo, "exames e procedimentos recomendáveis para o diagnóstico e tratamento das anomalias da diferenciação sexual” (CONSELHO FEDERAL DE MEDICINA, 2003).

Destarte, sob a perspectiva aqui defendida, deve-se aguardar a manifestação de vontade do indivíduo intersex que apresente condições em definir e adotar a sua identidade sexual e de gênero. Somente então, procedimentos mais invasivos, como o cirúrgico ou o tratamento 
hormonal, poderiam ser realizados, caso assim desejasse, priorizando a autodeterminação do sujeito e sua livre escolha.

\section{A IDENTIDADE COMO DIREITO DA PERSONALIDADE}

Dentro da perspectiva dos direitos da personalidade, o Código Civil brasileiro tutela o direito ao nome, especialmente nos artigos 16 ao 19. Partindo de uma concepção tradicional, o nome é compreendido como o sinal identificador do indivíduo na sociedade, sendo conferida proteção ao nome em caso de uso indevido, com vistas a proteger o direito à identidade pessoal.

O direito à identidade é um direito de cunho moral, que se estabelece na relação entre o indivíduo e a sociedade, possibilitando a individualização da pessoa e impedindo que ela seja confundida com outra (BITTAR, 2015, p. 195). O bem jurídico que se pretende tutelar é a identidade, enquanto atributo inerente à personalidade humana.

De acordo com Bittar (2015, p. 196) o direito essencial é o direito ao nome, o qual compreende, no plano pessoal, o sobrenome (que designa o núcleo a que pertence o indivíduo), e o prenome (nome propriamente dito), além dos acessórios (como o pseudônimo, a alcunha e o hipocorístico).

O nome é o "sinal verbal que identifica imediatamente, e com clareza, a pessoa a quem se refere. Por meio do nome, o indivíduo é designado na língua que é comum aos outros, e a sua identificação é possível mesmo na sua ausência" (DE CUPIS, 2008, p. 179-180). O nome tem significativa importância social e jurídica quando se presta a individualizar as pessoas, de maneira que "a função identificadora é exercida, principalmente, através do nome" (DE CUPIS, 2008, p. 180).

Do mesmo modo, Diniz (2011, p. 144) afirma que o direito ao nome integra a personalidade "por ser o sinal exterior pelo qual se individualiza a pessoa, identificando-a na família e na sociedade".

Dentre as características próprias do nome civil, destacam-se a inestimabilidade (não pode ser valorado economicamente), obrigatoriedade (ainda que contra a vontade do titular), imutabilidade, irrenunciabilidade (não pode ser afastado pelo titular), oponibilidade a terceiros, sendo, porém, admitidas mitigações (BITTAR, 2015, p 197).

O nome pessoal, assim como os seus acessórios, pode ser adquirido pelo nascimento, casamento, por atribuição de terceiro, escolha ou adoção, devendo ser registrado no competente cartório, afim de se conferir publicidade e proteção. (BITTAR, 2015, p 197).

Rev. de Gênero, Sexualidade e Direito | e-ISSN: 2525-9849 | Porto Alegre | v. 4 | n. 2 | p. 137 - 154 | Jul/Dez. 2018 
Em que pese a disposição sobre os direitos da personalidade no Código Civil Brasileiro, inclusive no que tange ao direito ao nome, o procedimento relativo ao registro está disciplinado na Lei $n^{\circ}$ 6.015/1973, Lei de Registros Públicos. Referida lei estabelece o procedimento de registro das pessoas naturais e jurídicas, especificando os elementos necessários ao assentamento, bem como as condutas que devem ser realizadas pelo oficial, e trata sobre a possibilidade de ajuizamento de ação para retificação do registro. Nesse ínterim, dispõe sobre o registro do neonato, que nos interessa no presente trabalho.

Imperioso ressaltar que a falta de acesso ao registro civil e à identificação pública impossibilita a fruição de outros direitos decorrentes do registro civil regular (BITTAR, 2015, p. 196). Por certo, a ausência de registro civil inviabiliza o acesso à educação, à saúde, aos direitos políticos e outros. Diante do valor jurídico atribuído ao registro, a Constituição Federal garantiu a gratuidade do registro civil de nascimento aos reconhecidamente pobres, conforme artigo 5', LXXVI, “a”.

O direito à identidade é um direito fundamental personalíssimo, intimamente ligado à dignidade da pessoa humana, reconhecido a todo o ser humano e resguardado por importantes instrumentos normativos, como a Declaração Universal dos Direitos Humanos, a Convenção dos Direitos da Criança, a Constituição Federal do Brasil e o Código Civil de 2002. O seu início formal se dá a partir do Assentamento Civil de Nascimento, que se afigura como a própria condição civil, assegurando direitos já estabelecidos e afirmando o indivíduo como pessoa. (FRASER; LIMA, 2012, p. 08).

O Estatuto da Criança e do Adolescente também confere proteção à identidade. Estabelece em seu artigo 15 o direito à liberdade, ao respeito e à dignidade, enquanto pessoas em processo de desenvolvimento. Em seu artigo 17 dispõe sobre a abrangência do direito ao respeito, consistindo na inviolabilidade da integridade física, psíquica e moral, compreendendo a preservação da identidade, assim como da imagem, da autonomia, dos valores, ideias, crenças, espaços e objetos pessoais da criança e do adolescente (BRASIL, 1990).

Ainda que a proteção conferida ao nome, ao sobrenome e a seus acessórios garanta o direito à identidade, outros são os sinais que identificam e caracterizam a pessoa no seu convívio social e que tornam possível distingui-la das demais.

Mesmo diante da importância que o nome assume, a identidade vai além da mera nomeação, encontrando eco nas experiências sociais, culturais, políticas e ideológicas das quais a pessoa toma parte. Identidade, portanto, parte do pressuposto de como o indivíduo se reconhece e como é reconhecido pela sociedade, e esse reconhecimento é muito mais complexo que os rótulos simplistas que costumam se apresentar no campo das relações sociais. (FACHIN, 2014, p. 41). 
A própria caracterização da identidade e dos seus elementos tem ganhado novos contornos. Nas palavras de Taylor (2011, p. 46): "nossa identidade é mais profunda e mais multiforme que qualquer de nossas possíveis articulações dela". O autor ainda caracteriza a identidade como aquilo que nos possibilita determinar o que é ou não importante para nós (TAYLOR, 2011, p. 47).

De outro modo, a concepção original do direito à identidade é renovada com as perspectivas interdisciplinares, de maneira que, sob este viés, a identidade se forma no diálogo com o outro, sendo construída de maneira individual e coletiva, simultaneamente (CHOERI, 2010, p. 72;166).

Em face da dinamicidade conferida ao direito à identidade, sua proteção jurídica não pode se manter estática, sob pena violar esse direito e inviabilizar a tutela de direitos fundamentais.

Dessa forma, o aprofundamento na compreensão do que seja a construção da identidade implica também a ampliação de sua tutela: protege-se o sujeito não apenas contra a imputação de uma identidade que não seja compatível com a sua, mas igualmente contra a ausência ou insuficiência do reconhecimento de sua identidade. (KONDER, 2018, p. 05).

Dentre as novas perspectivas da identidade pessoal, a sexualidade vem se destacando como elemento definidor de uma identidade, trazendo debates sobre orientação sexual e identidade de gênero (CUNHA, 2015, p. 02). Conforme destaca Cunha, o primeiro traço identificador da pessoa, logo que ela nasce, é a sua adequação entre uma das modalidades estabelecidas dentro do sexo binário (homem ou mulher), obtida pela observação fenotípica da criança, revelando que a sexualidade tem como parâmetro a aparência da região genial, ao menos de início.

Contudo, a ocorrência de má formação da genitália externa pode dificultar a constatação da sexualidade pela aparência física, situação complexa diante da necessidade de reconhecimento do sexo no atestado de nascido vivo e no assentamento de nascimento (CUNHA, 2015, p. 02).

Ocorre que o nascimento de crianças intersexuadas muitas vezes impõe um limite objetivo ao Assentamento Civil destes indivíduos, em face da impossibilidade da declaração imediata do sexo e, consequentemente, do prenome dessas crianças. No Brasil, o sexo civil tem como base unicamente o sexo morfológico do indivíduo e, em casos de crianças com genitália ambígua, torna-se inviável o seu registro imediato, em razão da incerteza quanto ao sexo e ao nome, feminino ou masculino, do neonato. (FRASER; LIMA, 2012, p. 07). 
Nesse ínterim, a necessidade de reconhecer o indivíduo como pertencente ao sexo feminino ou masculino para fins de registro civil, e a obrigatoriedade da referida informação, pode ocasionar uma inquietação em pais de crianças intersex no que tange à adequação dos corpos das crianças à binariedade homem/mulher. Tais alterações podem causar sérios danos à formação da identidade do neonato, e por conseguinte, danos de ordem psicológica ou física.

É importante considerar que o neonato em condição de intersexualidade apresenta ambiguidades biológicas que podem refletir em seu corpo, inclusive pela ambiguidade genital, devendo, então, ser considerada toda a proteção que merece para seu livre desenvolvimento e formação de sua identidade também no aspecto do corpo e da identidade sexual.

Ressalta-se que: "tal como na discussão do direito ao nome (...) o corpo também cumpre uma função social importante na conformação de uma identidade do sujeito e mesmo de sua própria felicidade" (FACHIN, 2014, p. 47).

No que tange à identidade sexual do indivíduo, é importante considerar que ela se constitui de aspectos biológicos, psicossociais, e legais, de maneira que este último é estabelecido no registro civil quando do nascimento da criança e baseado no aspecto morfológico dos genitais externos.

Portanto, compreende-se que a formação da identidade sexual do indivíduo é o resultado da integração dos elementos biológico, psicossocial e civil. Neste contexto, a criança intersexuada pode ser entendida como aquela que apresenta distúrbios, anomalias ou incongruências em qualquer dos seus sexos cromossômico, endócrino ou morfológico, ocasionando ambiguidades no componente biológico da sua identidade sexual. (FRASER; LIMA, 2012, p. 02).

Contudo, as ambiguidades biológicas da criança intersex não podem ser entrave à formação da identidade sexual, sendo a própria sexualidade compreendida por diversos fatores, os quais devem ser considerados pelo Direito e pela legislação como forma de se garantir proteção ao indivíduo.

A Psicologia define a sexualidade humana como uma combinação de vários elementos: o sexo biológico (o sexo que se tem); as pessoas por quem se sente desejo (a orientação sexual); a identidade sexual (quem se acha que é); e o comportamento ou papel sexual. Como os fatos acabam se impondo ao Direito, a rigidez do registro identificatório da sexualidade não pode deixar de curvar-se à pluralidade psicossomática do ser humano. (DIAS, 2017).

Considerando os vários matizes que constituem a identidade sexual, não é possível restringi-la ao sexo registral contido no assentamento lavrado logo após o nascimento, especialmente quando o sexo civil demandou escolha de um terceiro, seja de um médico ou dos pais do sujeito nascido com ambiguidade no sexo biológico. Portanto, a pessoa nascida com 
ambiguidade genitália ou outra alteração que impossibilite a identificação sexual não pode ter sua autonomia devorada pela necessidade jurídica de adequação do sexo civil à binariedade homem/mulher.

Os novos debates sobre identidade pessoal devem pautar o reconhecimento jurídico e social da liberdade de construção da própria identidade, e viabilizar o registro civil de crianças intersex de maneira a garantir outros direitos decorrentes do registro, bem como o próprio registro sem qualquer constrangimento.

\section{REGISTRO CIVL E INTERSEXUALIDADE}

O registro civil confere formalmente o direito à identidade do indivíduo, reconhecendoo no plano jurídico e garantindo direitos decorrentes da personalidade jurídica da pessoa natural.

A Lei 6.015/1973 dispõe sobre o registro decorrente do nascimento das pessoas naturais nos artigos 50 a 66. Estabelece em seu artigo 58 que o prenome será definitivo, admitindo-se a sua substituição por apelidos públicos notórios. Admite também, a teor do parágrafo único do mesmo artigo, a substituição do prenome como forma de proteger a testemunha que contribui para a apuração de crime, e se encontra coagida ou ameaçada, sendo necessária a determinação judicial, em sentença, após ouvido o Ministério Público.

De acordo com a Lei de Registros Públicos, o registro do nascimento ocorrido dentro do território nacional deverá ser realizado no prazo de quinze dias, a teor do artigo 50, caput. Excepcionalmente, o prazo poderá ser ampliado para até três meses, em lugares distantes mais de trinta quilômetros da sede do cartório.

Dentre os requisitos que devem necessariamente constar no assentamento do registro civil, o artigo 54 da lei em comento estabelece o sexo do registrando, inexistindo qualquer menção ao procedimento que deve ser realizado em caso de indeterminação do sexo do recémnascido.

Em nosso País, um RN (recém-nascido, anotação nossa) com genitália ambígua não pode ser registrado e costuma ser designado como RN de ... (nome da mãe) até o esclarecimento médico do problema orgânico que deu origem ao quadro, orientando a tomada de decisão para o registro civil do lactente e o devido encaminhamento médico para esclarecimentos técnicos. Nessas condições, os RNs são preferencialmente seguidos por equipes multidisciplinares formadas por endocrinologistas, geneticistas clínicos e cirurgiões pediátricos, e a definição da conduta depende de exames de citogenética (cariótipo) e da avaliação hormonal. Para as decisões de registro e das correções clínico-cirúrgicas a equipe de trabalho leva em consideração a vontade expressa pela família e também, quando possível, a da criança 
e pode lançar mão do parecer de outros profissionais nesse contrato informal para o tratamento. (CERQUEIRA, 2011, p. 51-52).

Constatada a condição de intersexualidade do neonato, pode-se questionar como proceder ao registro civil. A Lei de Registros Públicos estabelece o prazo de 15 dias do nascimento para se proceder ao registro. Contudo, conforme pontua Dias (2017), nesse período nenhum procedimento cirúrgico terá sido levado a efeito, de maneira que o sexo poderia ser indicado pelos pais: "certamente, os pais indicarão o sexo que tem a aparência prevalente, e, se tal não existir, farão o registro com a identidade que desejavam que o filho tivesse".

Determinada a identidade sexual do recém-nascido por meio de indicação médica, com a definição cirúrgica da genitália, poderia ocorrer a não identificação do indivíduo com o sexo a ele imposto, sendo posteriormente necessária a retificação do registro, com autorização judicial (DIAS, 2017). Tal situação poderia se dar uma vez que não há a possibilidade de que os registradores não preencham a indicação do sexo do registrando, deixando o espaço em branco, e diante da ausência da indicação de sexo indefinido ou sexo indeterminado, como ocorre na Alemanha, Austrália e França (DIAS, 2017).

Pontua-se que a questão do registro vai além da identidade formal. A crença de que o sexo deve se identificar por completo em todos os níveis (biológico, psicossocial e jurídico), sendo classificado necessariamente como masculino ou feminino, atendendo aos padrões socialmente estabelecidos, pode levar a alterações abruptas no corpo do indivíduo, de maneira precoce, ainda que sem o seu consentimento, como no caso de cirurgias irreversíveis realizadas em recém-nascidos.

Os casos de intersexo geram na sociedade e no meio médico a busca por medidas corretivas para um corpo considerado deformado, contudo, a escolha do indivíduo deve-se sobrepor à vontade médica e familiar (DIAS, 2017).

Inexiste consenso entre operadores do direito e profissionais da saúde, de maneira que a família pode optar pelo retardamento do registro civil, aguardando as conclusões de exames e da definição sexual pela equipe multidisciplinar, situação que ocasionará a inexistência jurídica da criança e, consequentemente, a deixará sem acesso a direitos. De outro modo, optar pelo registro imediato sugere uma eventual necessidade de ajuizar Ação de Retificação do Registro Civil, em momento posterior, para corrigir o nome e o sexo civil, considerando a não correspondência do sexo registrado com o sexo definido após os procedimentos médicos. Contudo, nota-se que referida ação proporciona mais um empasse para a família, diante dos 
desgastes emocionais e do tempo, além de que há uma violação ao direito à identidade da criança intersexual e à sua dignidade durante este lapso (FRASER; LIMA, 2012, p. 07).

A situação de invisibilidade ${ }^{2}$ em que as pessoas intersexo vivem gera estigma e contribui para que não sejam tomadas medidas legais que garantam o direito ao registro independente da definição sexual. Ainda, dificultam o acesso a informações relativas à caracterização da condição de intersexo, ao registro e aos acompanhamentos médicos e psicológicos. Nesse sentido, a cartilha "Dignidade da Criança em situação de Intersexo: orientações para a família", pode auxiliar a família da criança intersexo. No que tange ao registro, a Cartilha orienta aos pais que decidem por não realiza-lo, a acionarem o Judiciário requerendo o registro especial provisório da criança, com a indicação dos nomes dos pais e dos avós, além da data e do local de nascimento (CANGUÇU-CAMPINHO; LIMA, 2014, p. 18).

Ainda que haja omissão legislativa quanto ao tema, projetos de lei buscam amenizar impasses a que as pessoas intersex são submetidas.

O Projeto de Lei 5002/2013 dispõe sobre o direito à identidade de gênero e busca alterar o artigo 58 da Lei de Registros Públicos, de maneira a facilitar a alteração do nome nos casos de discordância com o nome e o sexo pré-definidos no registro civil, passando a constar a seguinte redação:

Art. 58 . O prenome será definitivo, exceto nos casos de discordância com a identidade de gênero auto-percebida, para os quais se aplicará a lei de identidade de gênero. Admite-se também a substituição do prenome por apelidos públicos notórios. (CÂMARA DOS DEPUTADOS, 2013).

Chamada de Lei de Identidade de Gênero, o referido projeto busca reconhecer o direito à livre identificação de gênero e ao seu pleno desenvolvimento, podendo envolver alterações na aparência, na função corporal, vestimentas, e demais formas de manifestação identitária, escolhidas livremente pela pessoa. Garante a retificação registral do sexo e a mudança do prenome e imagem constantes na documentação pessoal, sem qualquer requisito de intervenção cirúrgica, terapias hormonais, tratamentos médicos ou psicológicos, ou ainda autorização judicial.

\footnotetext{
${ }^{2}$ Diante da invisibilidade dos intersexuais na luta pela identidade sexual e de gênero, a Comissão da Diversidade Sexual da Ordem dos Advogados do Brasil inseriu a letra "I" na sigla LGBTI, originalmente representativa da população lésbica, gay, bissexual, travesti, transexual, e incluindo a intersexual (DIAS, Maria Berenice. Homoafetividade e direitos LGBTI. 2. ed. e-book. baseada na 7. ed. impressa. São Paulo: Revista dos Tribunais, 2017).
} 
Contudo, ainda que referida lei facilite alterações relativas à não identificação da pessoa com o sexo registrado, situação esta que pode ocorrer com pessoas intersex que tenham seu sexo pré-definido por seus pais quando do nascimento, ainda assim não abrange a questão do registro sem identificação do sexo.

Já no Senado Federal tramita o Projeto de Lei $n^{\circ}$ 134/2018, que institui o Estatuto da Diversidade Sexual e de Gênero. O Estatuto visa promover a inclusão independentemente da orientação sexual ou identidade de gênero, e combater e criminalizar a discriminação e a intolerância. Veda, em seu artigo 35, a realização de intervenção médico-cirúrgica de caráter irreversível, em recém-nascidos e crianças intersexuais, quando ausentes razões de saúde clínica. Ademais, garante que a hormonoterapia ou procedimentos não-cirúrgicos para adequação de gênero possam ser realizados com indicação médica e multidisciplinar a partir da idade em que a criança expressar sua identidade de gênero (art. 36), e dispõe sobre a cirurgia de redesignação sexual somente após atingida a maioridade civil (art. 37) ${ }^{3}$.

O Estatuto propõe que transgêneros e intersexuais possam utilizar o nome social, independente de retificação no assentamento do Registro Civil ${ }^{4}$. Do mesmo modo, trata sobre a retificação do nome e da identidade sexual, independente da realização de cirurgia de transgenitalização, apresentação de perícias, ou laudos, de maneira que a alteração possa ser requerida diretamente no Cartório de Registro Civil, sem a necessidade de ação judicial ou representação por advogado 5 .

\footnotetext{
${ }^{3}$ Nesse ponto o Estatuto se insurge à opinião trazida no presente trabalho, pois defendemos que a maioridade civil não é sinônimo de uma completa formação da identidade sexual do indivíduo. Assim, argumentamos pelo acompanhamento médico e psicológico como forma de reconhecer a possibilidade de intervenção cirúrgica, juntamente com a manifesta vontade da criança ou do adolescente intersex, de maneira que o procedimento possa ser realizado ainda que não atingida a maioridade civil, e desde que não haja risco à saúde ou à vida.

${ }^{4}$ No Projeto: "Art. 38. É garantido aos transgêneros e intersexuais o direito ao uso do nome social, pelo qual são reconhecidos e identificados, independente da retificação no assento do Registro Civil:

I - em todos os órgãos públicos da administração direta e indireta, nas esferas federal, estadual, distrital e municipal;

II - em fichas cadastrais, formulários, prontuários, entre outros documentos do serviço público em geral;

III - nos registros acadêmicos das instituições de ensino fundamental, médio e superior, tanto na rede pública como na rede privada.

$\S 1^{\circ}$ A Identificação Civil Nacional - ICN, além do nome que consta em seu registro civil, deverá conter campo destinado ao nome social.

$\S 2^{\circ}$ A inclusão do nome social deve ocorrer mediante simples requerimento formulado diretamente junto ao Cartório do Registro Civil.

$\S 3^{\circ} \mathrm{O}$ tratamento pelo nome civil em desrespeito ao nome social, configura ilícito civil e enseja do reconhecimento da existência de dano moral." (SENADO FEDERAL. Projeto de Lei do Senado n ${ }^{\circ} 134$, de 2018. Institui o Estatuto da Diversidade Sexual e de Gênero. Disponível em: <https://www25.senado.leg.br/web/atividade/materias//materia/132701>. Acesso em: 10 jul. 2018).

${ }^{5}$ De acordo com a redação do Projeto: "Art. $40 . \S 1^{\circ}$ A alteração será averbada no Livro de Registro Civil de Pessoas Naturais.
}

Rev. de Gênero, Sexualidade e Direito | e-ISSN: 2525-9849 | Porto Alegre | v. 4 | n. 2 | p. 137 - 154 | Jul/Dez. 2018 
Em que pese tais projetos busquem proteger a autonomia da criança no que tange aos procedimentos médicos e tratamentos hormonais, bem como possibilitar a livre manifestação da identidade sexual e de gênero, trazendo facilidades para a alteração do registro civil, nenhum deles se propôs a tratar sobre a possibilidade de registro da criança intersex como pertencente a um terceiro sexo, ou como sexo indefinido ou indeterminado, casos que ocorrem em outros países.

Nesse sentido, Dias (2017) defende a necessidade de se garantir a opção de registro do intersexual como sexo indefinido ou indeterminado. Pontua que a definição de um sexo pelos pais do nascido intersexual pode afrontar a autonomia da vontade do indivíduo submetido a cirurgias irreversíveis sem sua manifestação.

Ainda que não seja objeto dos projetos de lei mencionados no presente trabalho, a possibilidade de se garantir a opção de registro como sexo indefinido ou indeterminado também merece ser debatida. Tal viabilizaria o direito ao registro civil e os direitos dele decorrentes, tão logo tenha nascido o indivíduo intersex, sem a necessidade de expor pais e médicos a uma escolha precoce e feita sem a autonomia do indivíduo.

\section{CONSIDERAÇÕES FINAIS}

A legislação pátria é insuficiente para tutelar a complexidade na qual a condição de intersexualidade é envolta. Diante do desamparo legal, pais e profissionais da saúde recorrem a procedimentos, inclusive irreversíveis, na tentativa de adaptar os corpos do recém-nascido intersexo, afim de encaixá-lo no padrão binário com uma identidade sexual compatível com o que impõe o registro civil.

A escolha dos pais e médicos pela realização de cirurgias de adaptação sexual, tratamentos hormonais ou outros, de cunho irreversível, não devem prosperar, porquanto os procedimentos desrespeitam a autonomia individual do sujeito na busca pela sua identidade sexual e de gênero. Ademais, a irreversibilidade dos procedimentos pode dificultar posterior alteração, requerida pelo próprio indivíduo. As cirurgias e tratamentos apenas se mostram

$\S 2^{\circ}$ Nas certidões não podem constar quaisquer referências à mudança levada a efeito, a não ser a requerimento da parte ou por determinação judicial.

$\S 3^{\circ}$ No caso de crianças e adolescentes, o pedido de retificação deve ser feito pelos pais ou responsáveis, ouvido o Ministério Público.

$\S 4^{\circ} \mathrm{A}$ falta de consentimento dos pais ou responsáveis pode ser suprida judicialmente.” (Ibidem). 
viáveis e necessários havendo risco à saúde e à vida da pessoa, diante da sobreposição desses direitos à autonomia de identificação sexual.

Independente da realização de procedimentos médicos, o acompanhamento psicológico e médico do intersex e de sua família se faz imprescindível. A orientação profissional concederá todo o apoio necessário às decisões relativas à disposição do corpo, bem como à identidade sexual e de gênero.

Por fim, alterações legislativas no que tange à obrigatoriedade de informar o sexo da criança quando do assentamento do registro civil merecem ser discutidas. A opção por deixar o campo destinado à indicação do sexo em branco, ou a possibilidade de assinalar como sexo indefinido ou indeterminado, ou ainda uma opção relativa a um terceiro sexo são posições já sustentadas e aceitas em outros países, e que poderiam ser melhor analisadas para sua aplicação no Brasil.

As opções de deixar em branco o espaço destinado à informação do sexo, ou a indicação do sexo como indefinido ou indeterminado permitiriam a autonomia na identificação sexual da pessoa intersex, de forma que ela estaria juridicamente isenta das proposições binárias de sexo, e livre para manifestar a sua identificação pessoal.

Já a indicação de um terceiro sexo, diverso do feminino e do masculino, poderia dar maior visibilidade às pessoas em condição de intersexo e às adequações que se fazem necessárias na garantia de seus direitos. De modo diverso, poderia gerar ainda mais estigma a uma pessoa que suplica por um direito tão básico quanto o do próprio registro de nascimento sem qualquer constrangimento.

De toda forma, são proposições que merecem ser discutidas em âmbito científico, legislativo e social, dando maior visibilidade, voz e garantindo plenamente o direito de registro civil aos intersexuais, independentemente da necessidade de se adequar à binariedade sexual, e sem qualquer constrangimento.

\section{REFERÊNCIAS}

BARROS, Inajá Guedes. Intersexualidade: Retificação de Registro Civil: Quesitos da Curadoria de Família. Justitia. São Paulo, v. 52, n. 150, abr./jun. 1990. Disponível em: <https://bdjur.stj.jus.br/jspui/handle/2011/24216>. Acesso em: 20 ago. 2018.

BENTO, Berenice; SILVA, Mikelly Gomes da; NUNES, Kenia Almeida. Corpos marcados: a intersexualidade como (des) encaixes de gênero. Cronos. Natal, v. 12, n. 2, p. 128-142, jul./dez. 2011. Disponível em: <https://periodicos.ufrn.br/cronos/article/view/3133>. Acesso em: 20 ago. 2018.

Rev. de Gênero, Sexualidade e Direito | e-ISSN: 2525-9849 | Porto Alegre | v. 4 | n. 2 | p. 137 - 154 | Jul/Dez. 2018 
BITTAR, Carlos Alberto. Os direitos da personalidade. 8. ed. rev. aum. e mod. São Paulo: Saraiva, 2015.

BRASIL. Constituição da República Federativa do Brasil de 1988. Disponível em: <http://www.planalto.gov.br/ccivil_03/constituicao/constituicao.htm>. Acesso em: 10 ago. 2018.

Lei $n^{\circ}$ 6.015, de 31 de dezembro de 1973. Dispõe sobre os registros públicos, e dá outras providências. Disponível em: <http://www.planalto.gov.br/ccivil_03/leis/L6015compilada.htm>. Acesso em: 10 ago. 2018.

Lei $n^{o}$ 8.069, de 13 de julho de 1990. Dispõe sobre o Estatuto da Criança e do Adolescente e dá outras providências. Disponível em: <http://www.planalto.gov.br/ccivil_03/LEIS/L8069.htm>. Acesso em: 04 set. 2018.

Supremo Tribunal Federal. Ação Direta de Inconstitucionalidade $n^{\circ}$ 4.275/DF. Relator Ministro Marco Aurélio. Julgado em 01 mar. 2018. Disponível em: <http://portal.stf.jus.br/processos/detalhe.asp?incidente=2691371>. Acesso em: 20 ago. 2018.

CÂMARA DOS DEPUTADOS. Projeto de Lei $n^{\circ}$ 5002/2013, de 20 de fevereiro de 2013. Dispõe sobre o direito à identidade de gênero e altera o art. 58 da Lei no 6.015 de 31 de dezembro de $1973 . \quad$ Disponível em: <http://www.camara.gov.br/proposicoesWeb/fichadetramitacao?idProposicao=565315>. Acesso em: 07 ago. 2018.

CANGUÇÚ-CAMPINHO, Ana Karina. A construção dialógica da identidade em pessoas intersexuais: o X e o Y da questão. Tese (Doutorado em Saúde) - Programa de Pós-Graduação em Saúde Coletiva do Instituto de Saúde Coletiva, Universidade Federal da Bahia. Salvador, 2012. Disponível em: <https://repositorio.ufba.br/ri/handle/ri/6776>. Acesso em: 05 set. 2018.

CANGUÇU-CAMPINHO, Ana Karina; LIMA, Isabel Maria Sampaio Oliveira. Dignidade da criança em situação de intersexo: orientações para família. Salvador: UFBA, 2014. Disponível em:

<http://www.sbp.com.br/fileadmin/user_upload/pdfs/CartilhaDireitosDignidade_DDS.pdf>. Acesso em: 18 jul. 2018.

CERQUEIRA, Elizabeth Kipman. Sexualidade, gênero e desafios bioéticos. São Caetano do Sul: Difusão Editora, 2011.

CHOERI, Raul Cleber da Silva. O direito à identidade na perspectiva civil-constitucional. Rio de Janeiro: Renovar, 2010.

CONSELHO FEDERAL DE MEDICINA. Resolução $n^{\circ} 1.664$, de 12 de maio de 2003. Dispõe sobre as normas técnicas necessárias para o tratamento de pacientes portadores de anomalias de diferenciação sexual. Disponível em: <https://www.abmes.org.br/legislacoes/detalhe/649/resolucao-cfm-n\%C2\%B0-1.664>. Acesso em: 10 jul. 2018. 
CUNHA, Leandro Reinaldo da. Identidade e redesignação de gênero: aspectos da personalidade, da família e da responsabilidade civil. Tese (Doutorado em Direito) - Programa de Estudos Pós-Graduados em Direito: Direito Civil Comparado, PUC. São Paulo, 2014.

. Identidade de gênero e a responsabilidade civil do Estado pela leniência legislativa. Revista dos Tribunais. São Paulo, v. 962, ano 104, p. 37-52, dez. 2015. Disponível em: <https://www.academia.edu/34676308/IDENTIDADE_DE_G\%C3\%8ANERO_E_A_RESPO NSABILIDADE_CIVIL_DO_ESTADO_PELA_LENI\%C3\%8ANCIA_LEGISLATIVA_Ou_ GENDER_IDENTITY_AND_THE_STATES_RESPONSIBILITY_FOR_LEGISLATIVE_L ENIENCY>. Acesso em: 20 ago. 2018.

DE CUPIS, Adriano. Os direitos da personalidade. 2. ed. São Paulo: Quorum, 2008.

DIAS, Maria Berenice. Homoafetividade e direitos LGBTI. 2. ed. e-book. baseada na 7. ed. impressa. São Paulo: Revista dos Tribunais, 2017.

DINIZ, Maria Helena. Curso de Direito Civil brasileiro: teoria geral do direito civil. 28. ed. São Paulo: Saraiva, 2011.

FACHIN, Luiz Edson. O corpo do registro no registro do corpo; mudança de nome e sexo sem cirurgia de redesignação. Revista Brasileira de Direito Civil. v. 1, p. 39-65, jul./set. 2014.

FRASER, Roberta Tourinho Dantas; LIMA, Isabel Maria Sampaio Oliveira. Intersexualidade e direito à identidade: uma discussão sobre o assentamento civil de crianças intersexuadas. Journal of Human Growth and Development. São Paulo, v. 22, n. 3, 2012. Disponível em: <http://www.revistas.usp.br/jhgd/article/view/46703>. Acesso em: 04 set. 2018.

SENADO FEDERAL. Projeto de Lei do Senado $n^{\circ}$ 134, de 2018. Institui o Estatuto da Diversidade Sexual e de Gênero. Disponível em: <https://www25.senado.leg.br/web/atividade/materias/-/materia/132701>. Acesso em: 10 jul. 2018.

SOUZA, Andréa Santana Leone de; SILVA, Mônica Neves Aguiar da. A tutela da criança intersex: uma análise principiológica. Revista de Gênero, Sexualidade e Direito. Salvador, v. 4, n. 1, p. 138 - 155, jan./jun. 2018.

TAYLOR, Charles. As fontes do self: a construção da identidade moderna. 3. ed. São Paulo: Loyola, 2011.

VIEIRA, Tereza Rodriques. O direito à saúde e o transexual. In: Novos Estudos Jurídicos, ano 4, n. 7, p 77-82, out. 1998. 